\title{
Welding Distortion Analysis of Hull Blocks Using Equivalent Load Method Based on Inherent Strain
}

\author{
Chang Doo Jang ${ }^{1}$, Yong Tae Kim ${ }^{2}$, Young Chun Jo ${ }^{2}$, Hyun Su Ryu ${ }^{2}$ \\ ${ }^{1}$ Research Institute of Marine Systems Engineering, Seoul National University, Seoul, Korea \\ ${ }^{2}$ Dept. of Naval Architecture \& Ocean Engineering, Seoul National University, Seoul, Korea
}

\begin{abstract}
Welding deformation reduces the dimensional accuracy of ship hull blocks and decreases productivity due to the correction work. Prediction and minimizing of welding distortion at the design stage will lead to higher quality as well as higher productivity. Therefore, it is strongly required to develop an effective method to accurately predict the weld distortion of hull blocks considering the fabrication sequences.

In the case of hull block welding work in shipyard, the welding process of curved stiffened plate has large amounts of workload. This paper suggests an efficient method for predicting the welding deformation of stiffened curved plates based on the inherent strain theory combined with the finite element method. The equivalent load was determined by integrating inherent strain components which are calculated in the vicinity of heat affected zone using the highest temperature and the degree of restraint. The welding distortion of curved stiffened panels under equivalent load are calculated by elastic analysis and compared with that by intensive elasto-plastic finite element analysis. It is verified that the proposed method has a high efficiency and accuracy.
\end{abstract}

\section{Keywords:}

Welding deformation; Curved stiffened plate; Inherent strain; Highest temperature; Degree of restraint; Finite element method.

\section{Introduction}

Nowadays, most commercial and naval ships are constructed by the block building method in shipyards. The blocks which constitute the ship hull are built in a series of production process and transferred to the preerection area for the preparation works including the correction of distortion. The distortion of a block is inevitably induced by welding and is accumulated during the sequential fabrication process.

As the block erection step accounts for about one-third of the whole shipbuilding process, the accuracy of a block's shape and size has a close relation with the overall efficiency of production in the shipyard. To increase the precision of fabrication, the welding distortion and the exact distortion margin at every fabrication stage should be estimated to meet the allowable tolerances of ship hull blocks.

The inherent strain method has been used as one of the most efficient analysis method to predict the welding deformation (Jang and Lee, 1999). Inherent strain method is an approach to calculate the deformation by elastic equivalent forces which are obtained by integration of inherent (irrecoverable) strain in the HAZ region. Due to its accuracy and efficiency, the inherent strain method will be able to substitute thermal elastoplastic 3-D FEM analysis which requires much more computing time.

The object of the present work is to develop an analysis method that can predict the welding distortion of stiffened flat plates considering the fabrication sequences, phase transformation and free convection (Jang and Lee, 2004; Jang, Ha, and Ko, 2003). Considering that the shape of a block is complex, the analysis method should predict the distortion in not only stiffened flat plate but also a stiffened curved plate.

The main purpose of this study is to develop the welding distortion analysis method for the stiffened curved plate by using the improved equivalent load method based on the inherent strain method, considering the fabrication sequences. For testing and evaluation of this method, various stiffened and curved plates, which have different curvature, will be analyzed with different fabrication sequences. The developed welding distortion analysis method can be applied to predict the plate forming by line heating (Jang, Ko and Seo, 1997) and line heating with weaving motions (Jang, Ha, and Kim, 2006) of a curved plate.

\section{Inherent strain due to welding}

The plastic strain that causes the welding deformation can be defined as the inherent strain. In the case that inherent stress is distributed in continuum, the stress 
can be removed by separating element from the continuum. The residual strain in the separated element is called the inherent strain(Fujimoto, 1967).

$\varepsilon^{*}=\frac{d S_{2}-d S_{0}}{d S_{0}}$

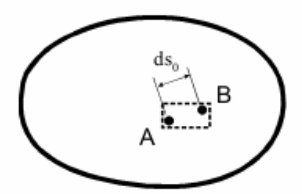

(a) Initial state (stress free)

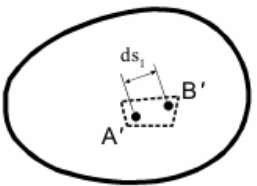

(b) Stressed state

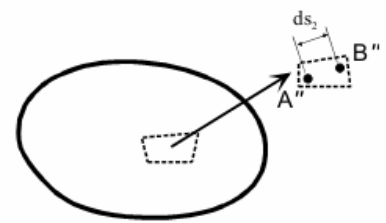

(c) Stress-released state by cutting

Fig. 1 Definition of inherent strain

General inherent strain by welding has six components $\varepsilon_{x}^{*}, \varepsilon_{y}^{*}, \varepsilon_{z}^{*}, \gamma_{x y}^{*}, \gamma_{y z}^{*}, \gamma_{z x}^{*}$. However, in the case that a plate has a large length/thickness ratio such as a ship hull plate, only two components $\varepsilon_{x}^{*}$ and $\varepsilon_{y}^{*}$ are dominant.

\section{Calculation of the inherent strain}

The inherent strain distribution can be formulated by using the simplified thermal elastic-plastic analysis model as shown in Figure 2(Jang 1996). The welding region, where the inherent strain occurs, can be modeled as a bar and a spring.

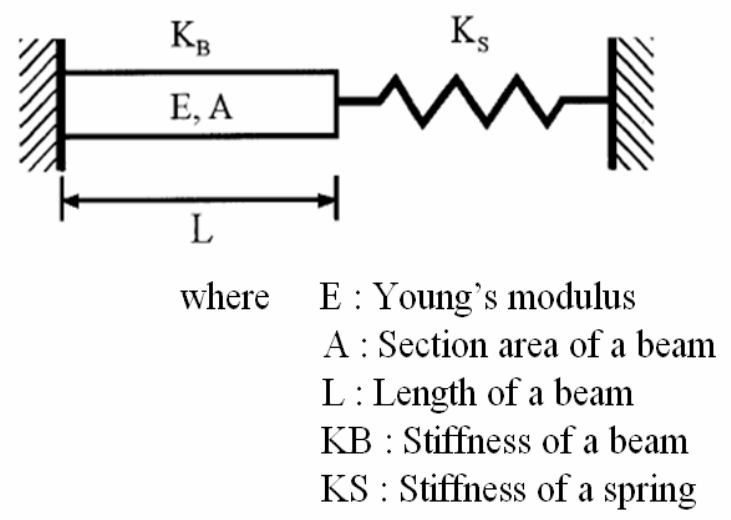

\section{Fig. 2 One-dimensional bar-spring model}

In the case of the curved plate, the bar-spring model can be applied. Although the plate has a curvature, the $\mathrm{HAZ}$ region is small enough to apply for the bar-spring model.

\section{Distribution of the highest temperature}

The plastic strain is dependent on the highest temperature as shown Fig.3, and the highest temperature is needed to calculate the inherent strain.

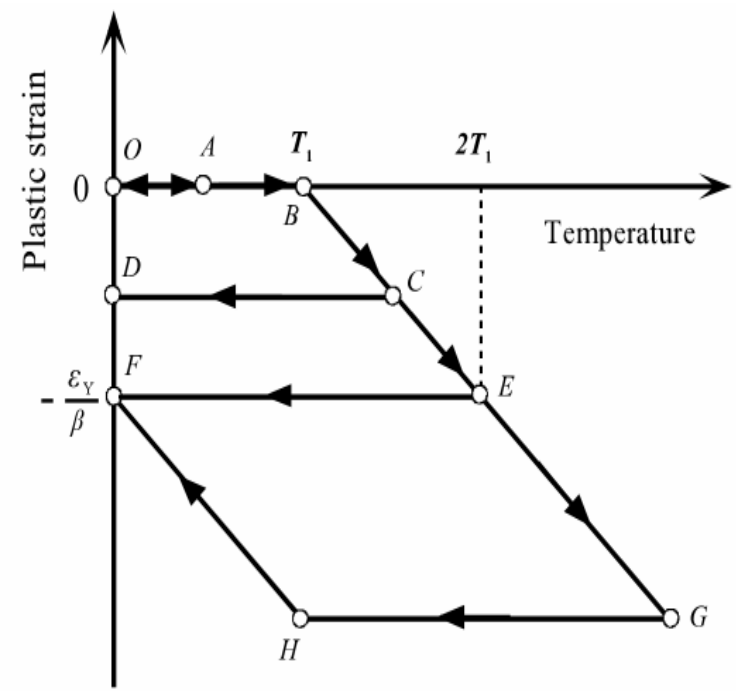

Fig. 3 Thermal history of plastic strain according to $\mathbf{T}_{\max }$

The highest temperature of each region is calculated by the FE heat transfer analysis as shown Figure 4.

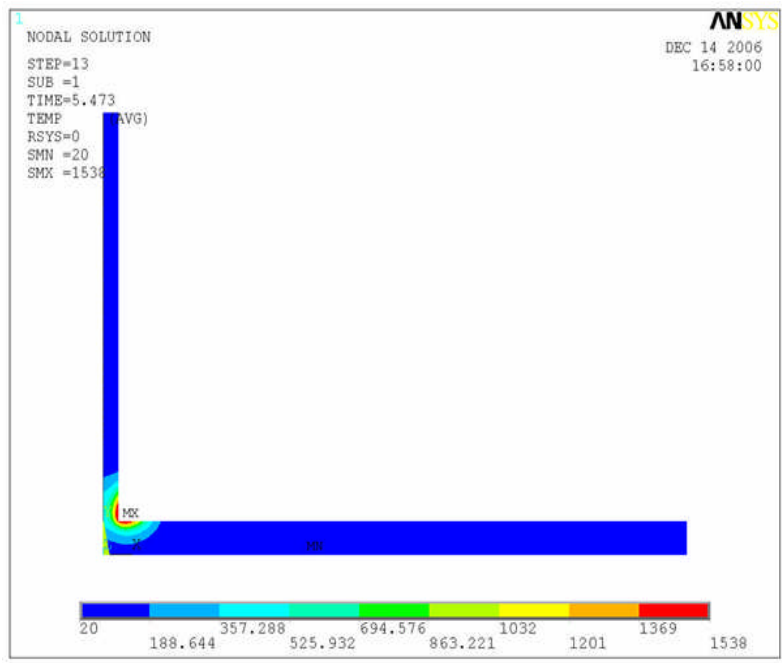

Fig. 4 Heat transfer analysis

\section{Calculation of degree of restraint}

The degree of restraint represents the level of resistance against the thermal deformation of the welding region. In order to calculate the degree of restraint, it is necessary to know the rigidity of the welding area and surround area. The unit load method is used to calculate the rigidity. The deformation from the elastic analysis of a stiffened plate under the unit load along the weld line is used to calculate the rigidity. 

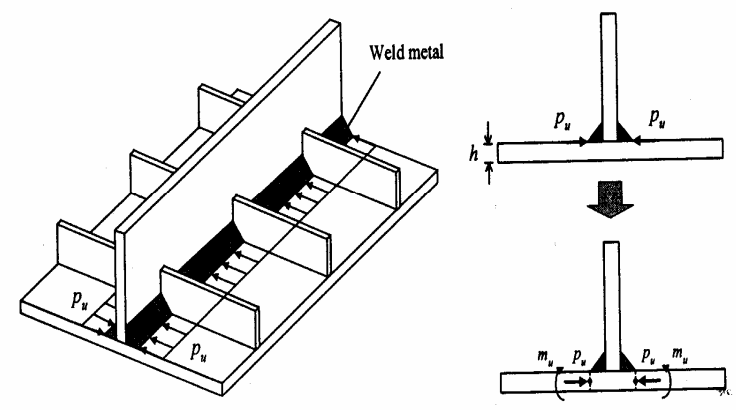

Fig. 5 Application of unit load along weld line

The distributed load $\mathrm{p}_{\mathrm{u}}$ shown in Fig 4 is applied at the end of leg length of the weld on the plate surface, so the distributed load $\mathrm{p}_{\mathrm{u}}$ and bending moment $\mathrm{m}_{\mathrm{u}}$ are applied in the middle plane of the plate.

$$
\begin{aligned}
& m_{u}=\frac{h}{2} \times p_{u} \\
& \delta_{S}=\delta+\frac{h}{2} \cdot \theta \\
& R_{S}=\frac{p_{u}}{\delta_{s}}=\frac{p_{u}}{\delta+\frac{h}{2} \cdot \theta}=k_{S}+K_{B}
\end{aligned}
$$

where $m_{u}$ : moment distributed along weld line

$$
\begin{aligned}
& p_{u}: \text { force distributed along weld line } \\
& \delta_{S}: \text { surface shrinkage } \\
& \theta: \text { rotation angle } \\
& R_{S}: \text { stiffness of structure } \\
& k_{S}: \text { stiffness of spring } \\
& K_{B}: \text { stiffness of bar }
\end{aligned}
$$

\section{Equivalent nodal loads}

The equivalent forces and moments are obtained by the inherent strain which is calculated by the highest temperature and the degree of restraint. There are four types of equivalent loads; transverse shrinkage force, transverse bending moment, longitudinal shrinkage force, and longitudinal bending moment as shown Figure 5.

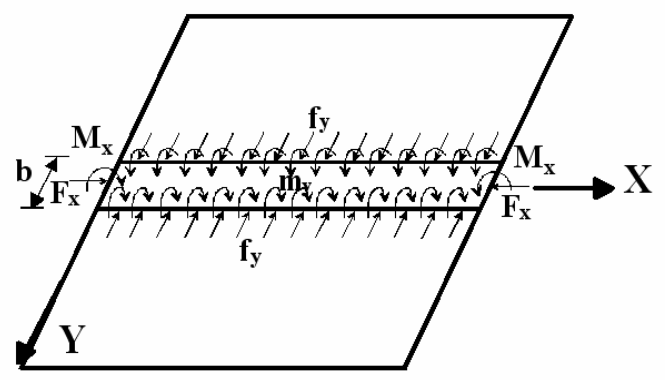

Fig. 6 Distribution of equivalent loads along weld line
Transverse shirinkage force

$$
f_{y}=\int_{A} E \varepsilon_{y}^{*} d A
$$

Transverse bending moment

$$
m_{y}=\int_{A} E \varepsilon_{y}^{*}\left(\frac{h}{2}+z\right) d A
$$

Longitudinal shirinkage force

$$
F_{x}=\int_{A} E \varepsilon_{x}^{*} d A
$$

Longitudinal bending moment

$$
M_{x}=\int_{A} E \varepsilon_{x}^{*}\left(\frac{h}{2}+z\right) d A
$$

where $\varepsilon_{x}^{*}$ : plastic strain in $x$-direction

$$
\begin{aligned}
& \varepsilon_{y}^{*}: \text { plastic strain in } y \text {-direction } \\
& h: \text { plate thickness }
\end{aligned}
$$

The longitudinal shrinkage force of a stiffened flat plate and a curved plate should be applied in different ways. As shown in Fig 6, the shrinkage force of the flat plate is applied at the both ends of the plate. In the curved plate case, however, the shrinkage force should be applied to each node toward the tangential direction of the welding line. Also, the application of equivalent load to a stiffened curved plate is shown in Fig 7.
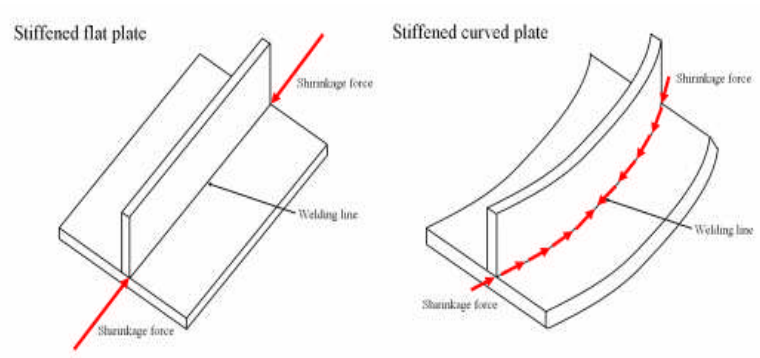

Fig. 7 Application of equivalent loads
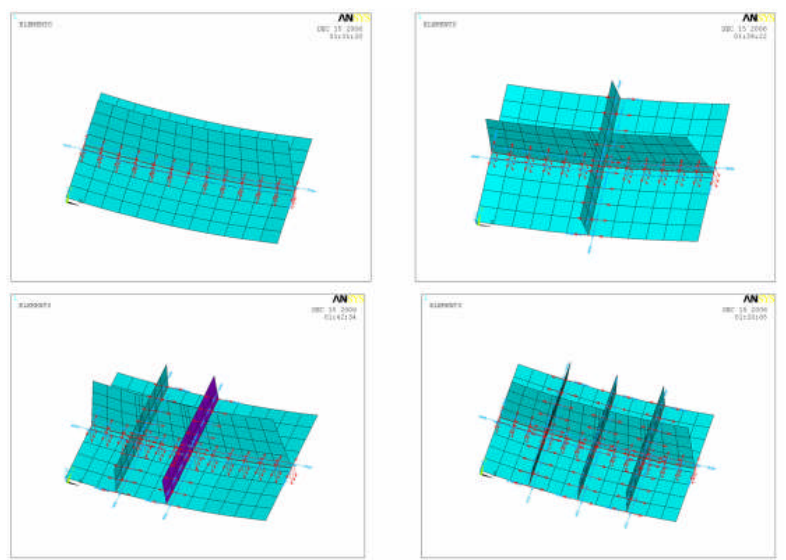

Fig. 8 Application of equivalent loads in FE model

\section{Simulation of welding deformation}

The welding deformation of stiffened curved plates was simulated by using both the inherent strain method and the FE analysis. The simulation procedures can be summarized into three steps. The first step analyzes the heat transfer; it calculates the highest temperature of each location with the welding information, considering convection on the plate surface. The second step 
calculates the degree of restraint by the unit load method using the FE analysis. The third step calculates the inherent strain components and their equivalent loads. Therefore, the welding deformation of the structure was solved by FE analysis.

\section{Welding deformation experiment}

The welding distortion experiment was performed for 4 kinds of stiffened curved plate models. As shown in Fig. 9, the experimental models have three kinds of curvatures ( $\rho=1000,2000,5000 \mathrm{~mm}$, respectively). The curvatures were selected by investigating actual fabrication data in the shipyards.

The girth length $(\rho \theta)$, breadth, and thickness of base plate are $1200(\mathrm{~mm}), \quad 800(\mathrm{~mm})$, and $16(\mathrm{~mm})$, respectively.

In order to study the effect of welding sequence on the welding distortion, the $2^{\text {nd }}$ and $3^{\text {rd }}$ experimental models were made to have the same curvature $(\rho=2000 \mathrm{~mm})$ but different welding sequences of case 1 and case 2 respectively. In case 1 ( $2^{\text {nd }}$ model $)$, the girder was welded after 3 longitudinal stiffeners are welded in order. In case 2 ( $3^{\text {rd }}$ model), the girder was welded at first and then 3 longitudinal stiffeners are welded in order.

As shown in Fig.10, the arc welding process was adopted. The welding condition was $30(\mathrm{~V})$ of voltage, 300 (A) of current, and $5(\mathrm{~mm} / \mathrm{s})$ of welding velocity, and each welding was conducted after the air cooling.

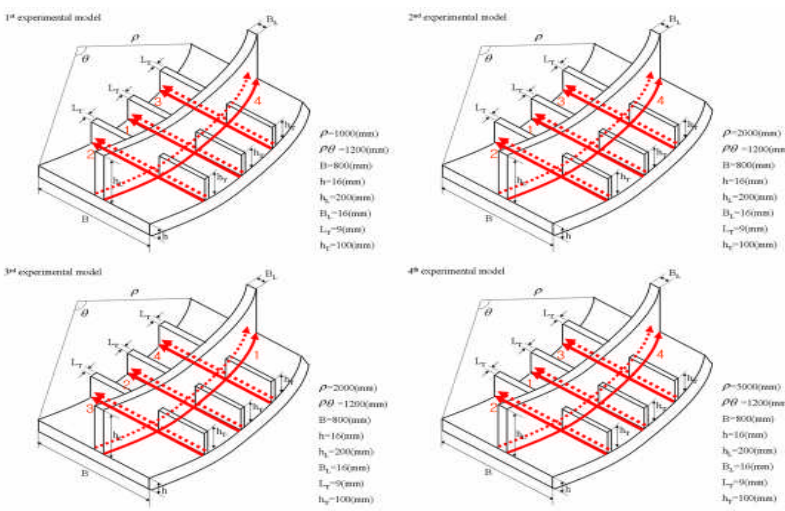

Fig. 9 Experimental models with the welding sequences
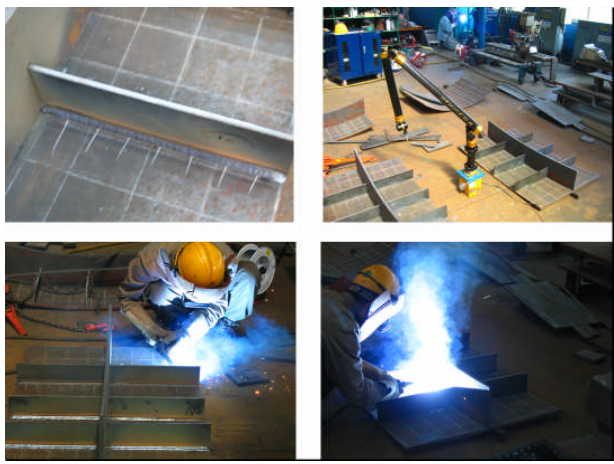

Fig. 10 Picture of welding distortion experiment

\section{Comparison of analysis and experiment}

$1^{\text {st }}$ experimental model
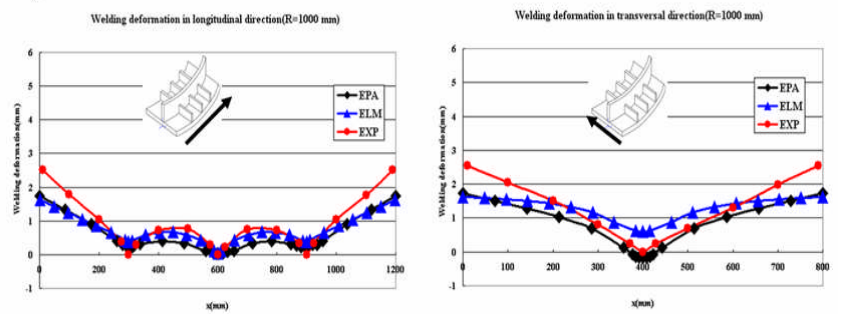

$2^{\text {nd }}$ experimental model
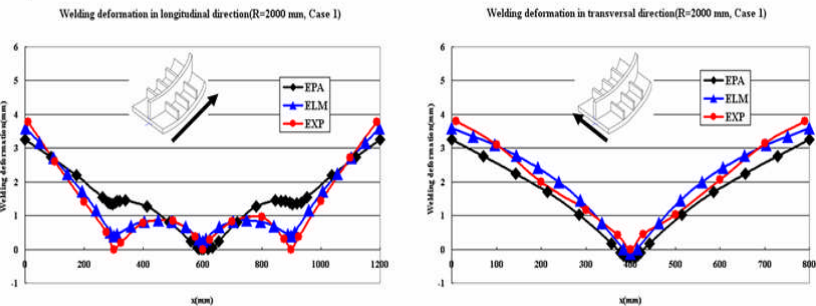

$3^{\text {rd }}$ experimental model

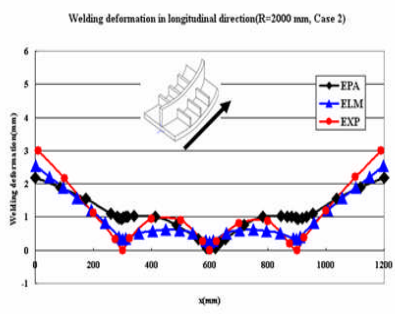

$4^{\text {th }}$ experimental model
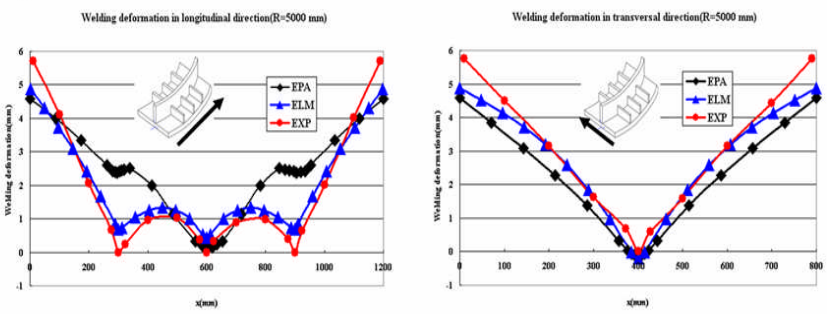

Fig. 11 Comparison of analysis and experiment

Table. 1 Analysis time

\begin{tabular}{|c|c|c|}
\hline & ELM & EPA \\
\hline $\begin{array}{c}\text { Analysis time } \\
\text { (Experimental model) }\end{array}$ & $3 \sim 4(\mathrm{~min})$ & $1.5 \sim 2($ day $)$ \\
\hline \multicolumn{2}{|c|}{ Pentium 4 CPU 3.20GHz, 2.00GB RAM } \\
\hline
\end{tabular}

As shown in Fig. 11, the welding deformation by the experiment show fairly good agreements with those by the ELM (Equivalent Load Method) suggested in this paper, but the welding deformation by the EPA (Thermal Elasto-Plastic Analysis) has a different tendency compared with the cases of ELM and EXP(Experiment). The discrepancy between EPA and EXP is remarkable especially at the location of $1^{\text {st }}$ and $3^{\text {rd }}$ longitudinal stiffeners.

In Fig. 11, the welding deformation increases with increasing radius of curvature, and the welding 
deformation with different welding sequence has a different value.

The welding deformation of case 1 ( $2^{\text {nd }}$ model) is larger than that of case 2 ( $3^{\text {rd }}$ model $)$. From this result, it is recommended that the curved girder should be welded first before the smaller longitudinal stiffeners are welded from the view point of welding distortion control.

As shown above, the proposed method can estimate the welding distortions of stiffened curved plates considering welding sequence according to the fabrication stages.

Due to its efficiency from elastic analysis and accuracy, the present method can provide a powerful solution to predict the welding distortion of actual ship hull blocks with high complexity in structural shape. Some welding distortion control of actual ship hull block to reduce the welding deformation can be devised.

\section{Conclusions}

The main conclusions of this study are summarized as follows:

(1) This paper suggests an efficient method (Equivalent Load Method) for predicting the welding deformation of stiffened curved plates based on the inherent strain theory combined with the finite element method.

(2) The proposed method can consider the various modes of welding distortions such as angular distortion, in-plane shrinkage, longitudinal and transverse bending deformations.

(3) The proposed method can estimate the welding distortions of stiffened curved plates considering welding sequence according to the fabrication stages.

(4) It is recommended that the curved girder should be welded first before the smaller longitudinal stiffeners are welded from the view point of welding distortion control.

(5) The welding distortion analysis by the proposed method showed fairly good agreements with those by experiment.

(6) Due to its efficiency and accuracy, the present method can provide a powerful solution to predict the welding distortion of actual ship hull blocks with high complexity in structural shape.

\section{Acknowledgement}

Part of this work was supported by the Ship Structures Committee (SSC). The authors wish to acknowledge for its support.

\section{References}

Jang, C.D. and Seo, S.I. (1996) "A study on the automatic fabrication of welded built-up beams." Trans. of the Society of Naval Architects of Korea, 33(1), pp. 206-213

Jang, C.D. and Lee, C.H.(1999) "Prediction of Welding Deformation of Stiffened Plates using inherent Strain Method" Proceedings of the Thirteenth Asian Technical Exchange and Advisory Meeting on Marine Structures, pp. 485-492

Jang, C.D., Lee, C.H. and Ko, D.E. (2002) "Prediction of welding deformations of stiffened panels" Journal of Engineering for the Maritime Environment, Vol. 216, No. M2, pp. 133-143

Kim, S.I., Han, J.M., Cho, Y.K., Kang, J.K. and Lee, J.Y. (1997) "A study on the accuracy control of block assembly in shipbuilding." ICCAS '97, pp. 367-381

Masubuchi, K. (1980) "Analysis of welded structures.”Pergamon Press, pp.239-243

Murakawa, H., Luo, Y. and Ueda, Y. (1997) "Prediction of welding deformation and residual stress by elastic FEM based on inherent strain" J. of the society of naval architects of Japan, 180, pp. 739751

Seo, S.I. and Jang, C.D. (1999) "A study on the prediction of deformations of welded ship structures." Journal of Ship Production, 15(2), pp. 73-81

Tekriwal, P.(1989) Three-dimensional transient thermo-elasto-plastic modeling of gas metal arc welding using the finite element method." U. of Illinois at Urbana-Champaign, Urbana, Ill., USA

Ueda, Y. and Ma, N.X. (1995) "Measuring Methods of Three-Dimensional Residual Stresses with Aid of Distribution Function of Inherent Strains(Report3)." Trans. of Japanese Welding Research Institute, 24(2), pp.123-130

Watanabe, M. and Satoh, K. (1965) "Welding mechanics and its applications. Asakura Publication, pp.367-411 